\title{
Expression of Angiotensin II Type 1 Receptor in Rat Bladder Smooth Muscle Cells in Response to a Streptzotocin Induced Diabetes Mellitus Model
}

\author{
Shohei Tobu ${ }^{\mathrm{a}}$ Mitsuru Noguchi ${ }^{\mathrm{b}}$ Teppei Hatada

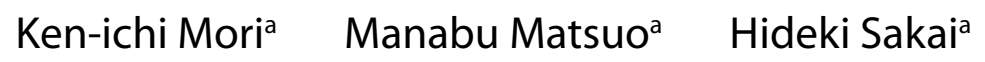 \\ aDivision of Nephro-Urology, Department of Translational Medical Sciences Course of Medical and Dental Sciences, Nagasaki University

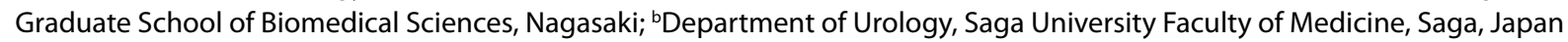

\section{Key Words}

Bladder • Diabetes mellitus • Renin-angiotensin system • Angiotensin receptor

\begin{abstract}
Introduction: The aim of this study was to investigate angiotensin II type 1 (AT1) receptors in rat bladder smooth muscle cells and alterations of AT1 receptors by diabetes mellitus and diuretic states. Materials and Methods: Diabetes and diuresis were induced in adult female rats by a single intraperitoneal injection of streptozotocin and feeding 5\% sucrose in water. Cystometry was performed on control, diuretic, and diabetic rats at 2 and 8 weeks after treatment. Immunohistochemical staining was used to detect expression of AT1 receptors in the bladder smooth muscle cell membrane. Results and Conclusions: In diabetic rats, expression of AT1 receptors in the bladder smooth muscle cell membrane increased at 2 weeks and further increased at 8 weeks. The local renin-angiotensin system in the rat bladder might be activated by the continuous hyperglycemia caused by intraperitoneal injection of streptozotocin administration.
\end{abstract}

Copyright $\odot 2012$ S. Karger AG, Basel

\section{KARGER}

Fax +41613061234

E-Mail karger@karger.ch

www.karger.com
(C) 2012 S. Karger AG, Basel

$1015-9770 / 12 / 0062-0062 \$ 26.00 / 0$

Accessible online at:

www.karger.com/cur

\section{Introduction}

Diabetes mellitus resulting as a long-term complication of the lower urinary tract is referred to as diabetic cystopathy [1]. Many factors probably contribute to the large capacity atonic bladder that characterizes diabetic cystopathy, including changes in the bladder smooth muscle [2]. Diuresis originating from diabetes mellitus causes increases in the bladder mass and changes contractility of the bladder strip [1,2].

Angiotensin II (AngII) is a potent vasoconstrictor and an integral part of the renin-angiotensin system (RAS), which regulates vascular tone, blood pressure, and sodium homeostasis. In addition to the systemic effects of this hormone, AngII may regulate cellular growth and function in several organ systems through a local RAS. In fact, there is increasing evidence suggesting that AngII is a local trophic factor in the wall of the bladder that is responsible for regulating smooth muscle cell growth under both normal and pathological conditions [3]. AngII may also play a role in the control of collagen production [4].

Previous studies demonstrated that local RAS plays a role in the functional disorder and fibrosis of many organs, including the kidneys [5], heart [6], lungs [7], and liver [8]. Moreover, the functional disorder and fibrosis caused by diabetes mellitus have been reported to be associated with a local RAS. 
Table 1. General characteristics and cystometry in control, diuretic and diabetic rats

\begin{tabular}{|c|c|c|c|c|c|c|c|}
\hline & $\begin{array}{l}\text { Rats } \\
\mathrm{n}\end{array}$ & $\begin{array}{l}\text { Rat } \\
\text { weight, g }\end{array}$ & $\begin{array}{l}\text { Bladder } \\
\text { weight, g }\end{array}$ & $\begin{array}{l}\text { Blood glucose } \\
\mathrm{mg} / \mathrm{dl}\end{array}$ & $\begin{array}{l}\text { Bladder } \\
\text { capacity, ml }\end{array}$ & $\begin{array}{l}\text { Voiding } \\
\text { efficiency, \% }\end{array}$ & $\begin{array}{l}\text { Max voiding } \\
\text { pressure, } \mathrm{ml} / \mathrm{cm} \mathrm{H}_{2} \mathrm{O}\end{array}$ \\
\hline Control & 7 & $256 \pm 6$ & $0.11 \pm 0.02$ & $93 \pm 5$ & $0.53 \pm 0.07$ & $91.5 \pm 1.4$ & $31.6 \pm 3.7$ \\
\hline \multicolumn{8}{|l|}{ Diuretic } \\
\hline Week 2 & 7 & $291 \pm 8^{*}$ & $0.20 \pm 0.02 *$ & $94 \pm 10$ & $1.29 \pm 0.15^{*}$ & $84.1 \pm 1.7$ & $31.8 \pm 4.7$ \\
\hline Week 8 & 7 & $342 \pm 6^{*}$ & $0.25 \pm 0.03^{*}$ & $97 \pm 3$ & $2.30 \pm 0.20 * \ddagger$ & $83.8 \pm 4.8$ & $33.3 \pm 5.1$ \\
\hline \multicolumn{8}{|l|}{ Diabetic } \\
\hline Week 2 & 7 & $219 \pm 9 * \dagger$ & $0.24 \pm 0.01 * \dagger$ & $401 \pm 23 * \dagger$ & $1.21 \pm 0.09 *$ & $57.6 \pm 4.8^{* \dagger}$ & $37 \pm 5.6$ \\
\hline Week 8 & 7 & $228 \pm 4 * \dagger$ & $0.41 \pm 0.02 * \dagger \|$ & $411 \pm 27 * \dagger$ & $2.58 \pm 0.15^{*} \|$ & $39.6 \pm 5.2 * \dagger$ & $39.5 \pm 5.9$ \\
\hline
\end{tabular}

* Significantly different from controls; $\uparrow$ Significantly different from diuretic rats of the same week; $\ddagger$ Significantly different from 2 weeks after treatment in diuretic rats; || Significantly different from 2 weeks after treatment in diabetic rats.

However, to our knowledge, whether the RAS is associated with bladder dysfunction caused by diabetes mellitus has not been investigated. Therefore, in the present study, we investigated angiotensin II type 1 (AT1) receptors in rat detrusor muscle and alterations of AT1 receptors by diabetes mellitus and diuretic states.

\section{Materials and Methods}

\section{Induction of Diabetes and Diuresis}

Diabetes was induced in adult female Sprague-Dawley rats (weight 230-280 g; Hilltop Laboratory, Pittsburgh, PA) by a single intraperitoneal injection $(65 \mathrm{mg} / \mathrm{kg})$ of streptozotocin (STZ) dissolved in an ice-cold $0.1 \mathrm{M}$ citrate buffer. The blood glucose level of the rats was checked 1 week after STZ injection and rechecked before death to confirm the presence of diabetes (blood glucose $>300 \mathrm{mg} / \mathrm{dl}$ ). Chronic diuresis was induced by feeding $5 \%$ sucrose in water. Normal rats were used as controls. The study protocol was approved by the Animal Ethics Committee at Nagasaki University Graduate School of Biochemical Sciences, Japan.

\section{Cystometry}

Cystometry was performed on control, diuretic, and diabetic rats at 2 and 8 weeks after treatment. The rats were anesthetized by intraperitoneal injection of $1 \mathrm{~g} / \mathrm{kg}$ body weight urethane. A PE50 catheter was inserted through the bladder apex into the lumen and then was connected to a pressure transducer and a microinjection pump (UD5500, Dantec, Denmark). Warmed saline was infused into the bladder at a rate of $10 \mathrm{ml} / \mathrm{h}$ for the control, diuretic, and diabetic rats.

Saline voided from the urethral meatus was collected and measured to determine the voided volume. After constant voided volumes were collected, the infusion was temporarily stopped and the post-void residual urine volume was measured by withdrawing intravesical fluid through the catheter, first by gravity and then by manually pressing the bladder. The bladder capacity was cal- culated as the sum of the voided volume and the volume of the post-void residual urine. The voiding efficiency was estimated as follows: voiding efficiency $(\%)=[($ voided volume/bladder capacity) $\times 100]$. The maximal voiding pressure was also measured.

\section{Histological Evaluation}

The bladder specimens of the control, diuretic and DM rats were fixed with $4 \%$ paraformaldehyde in phosphate-buffered saline (PBS) and embedded in paraffin. Sections were deparaffinized with xylene, and sequentially rehydrated in a graded ethanol series $(100,95,90,80$, and $70 \%)$ for 5 min each. The endogenous peroxidase activity was blocked by incubation in $3 \% \mathrm{H}_{2} \mathrm{O}_{2}$ in methanol for $15 \mathrm{~min}$. The sections were blocked with $1 \%$ goat serum and $5 \%$ skim milk, and incubated at $4^{\circ} \mathrm{C}$ for 24 hours with rabbit AT1 polyclonal antibody (Santa Cruz, California, USA) diluted 1:500 in PBS. After washing, the sections were incubated with Histofine Simple Stain Rat Max-PO (Nichirei Co., Tokyo, Japan) for 30 minutes at room temperature. The sections were stained with diaminobenzidine tetrahydrochloride (Nichirei Co., Tokyo, Japan), counterstained with hematoxylin and then mounted. The sections were also stained with Masson's trichrome staining to visualize the fibrosis of the bladder wall tissue.

\section{Statistical Analysis}

All data were expressed as means \pm SD. Student's $t$-test was used for comparisons between the control, diuretic and diabetic rat groups. Statistical significance was accepted at a value of $\mathrm{p}<$ 0.05 .

\section{Results}

\section{General Characteristics}

The body weight of the diuretic rats was significantly higher in comparison to that of control rats, and that of the diabetic rats was significantly decreased in comparison to that of control rats (table 1). The blood glucose levels 


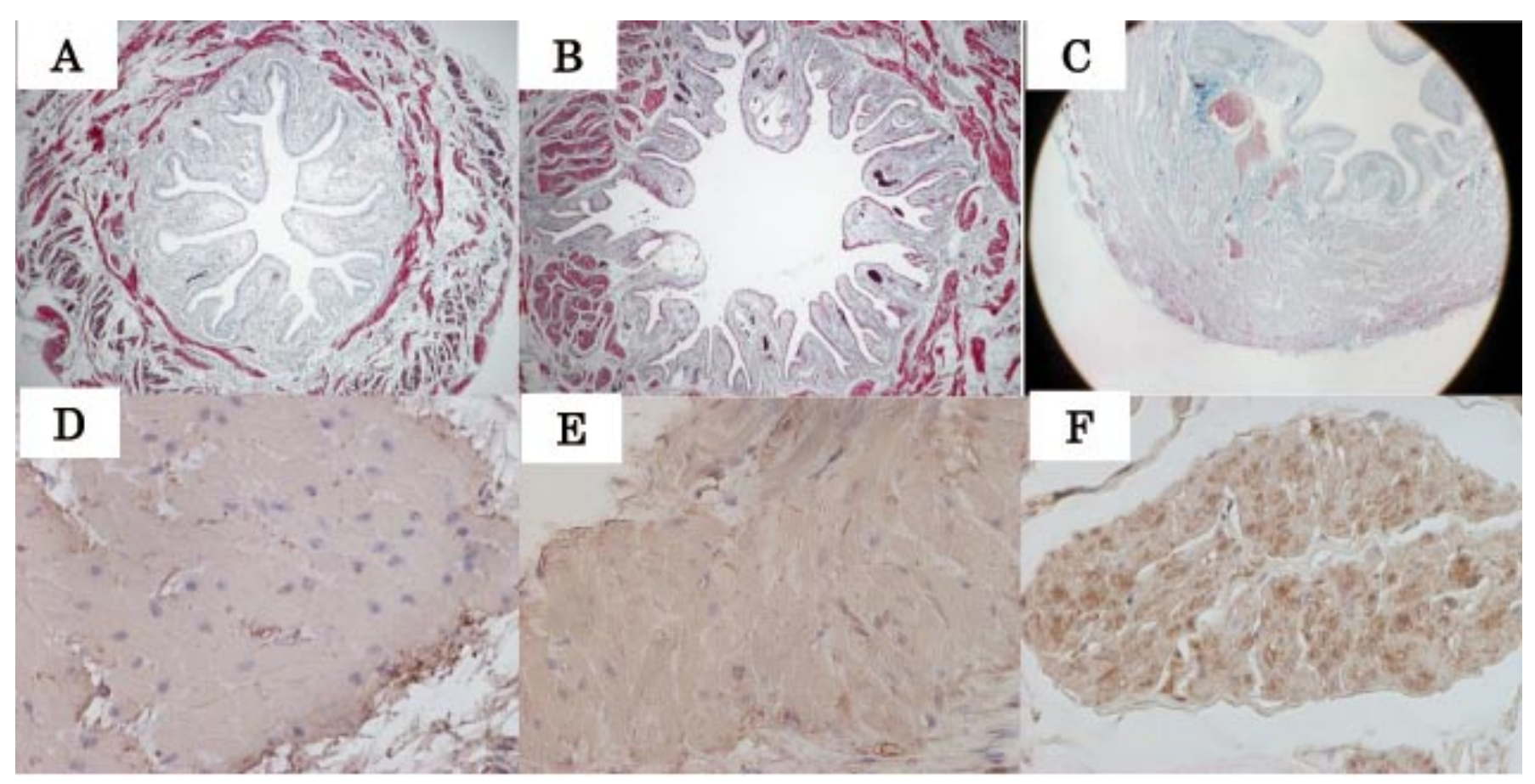

Fig. 1. Histological analysis of detrusor muscle cells 2 weeks after treatment in rats. Masson's trichrome staining $(\mathrm{A}-\mathrm{C})$. The color of the bladder smooth muscle 2 weeks after treatment in diabetic rats changed to blue. AT1 receptors sparsely expressed in detrusor smooth muscle membrane of control (D) and diuretic (E) rats. In the STZ-induced diabetic model, expression of AT1 receptors was increased in comparison to the control and diuretic rats $(\mathrm{F})$ (magnification of Masson's trichrome staining $\times 40$, magnification of immunohistochemical staining $\times 600)$.

of the diabetic rats were about 4 times higher than those of the control and diuretic rats. The bladder weights of the diuretic and diabetic rats were approximately twice those of the control rats.

\section{Cystometry}

Cystometry revealed that the mean bladder capacity and compliance increased in all treated rats compared with controls (table 1). Although diabetic rats had a significantly decreased voiding efficiency, the mean maximal voiding pressure was similar in all groups.

\section{Histological Findings}

Masson's trichrome staining revealed that the color of bladder smooth muscle cells changed from red to blue in 2 and 8 weeks after treatment in diabetic rats (fig. 1,2). This suggests that contentious hyperglycemia induced the observed fibrotic change in the bladder wall.
Immunohistochemical staining was done to detect expression of AT1 receptors in the bladder smooth muscle cell membrane. AT1 receptors were sparsely expressed in the bladder smooth muscle cell membrane in control and diuretic rats. However, in diabetic rats, expression of AT1 receptors in the bladder smooth muscle cell membrane was increased at 2 weeks, and was further increased at 8 weeks.

\section{Discussion}

AngII within the rat bladder tissue has been rarely studied, and to the best of our knowledge, AngII within the bladder of a diabetic rat model has not been investigated. A previous report indicated that hyperglycemia caused by STZ strongly induced expression of AT receptors in the rat kidney [9]. Our results suggested that the same phenomenon occurs in rat bladder tissue. 


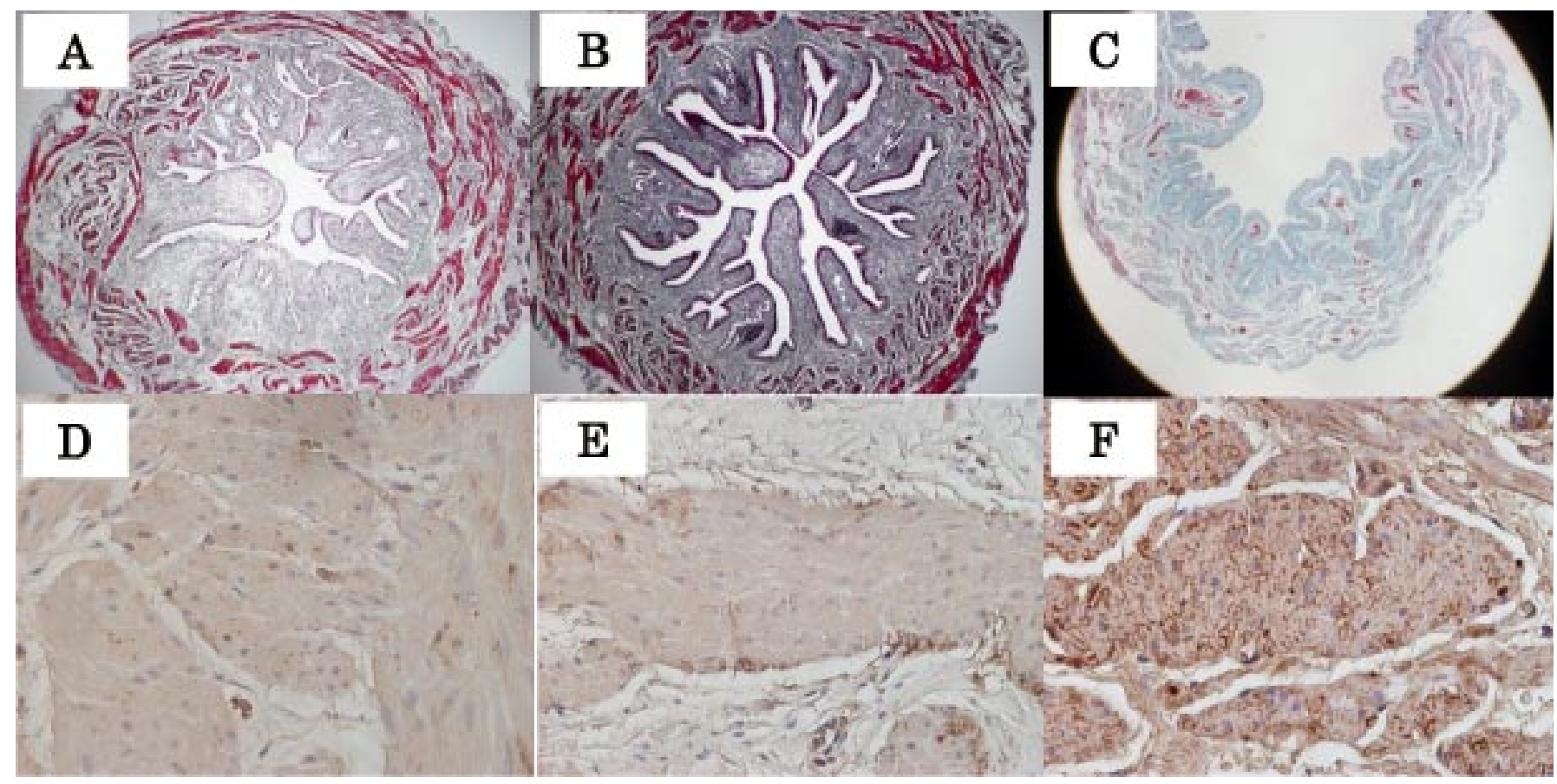

Fig. 2. Histological analysis of detrusor muscle cells 8 weeks after treatment in rats. Masson's trichrome staining (A-C). The color of the bladder smooth muscle 8 weeks after treatment in diabetic rats also changed to blue. In diabetic rats, expression of AT1 receptors in the bladder smooth muscle cell membrane was further increased at 8 weeks $(F)$. D: control rats E: diuretic rats (magnification of Masson's trichrome staining $\times 40$, magnification of immunohistochemical staining $\times 600)$.

Harrison-Bernard et al. [9] reported that expression of plasma AngII is increased in STZ-induced diabetic rats in comparison to control rats, and that the RAS is activated in rat kidney tissue by continuous hyperglycemia. Our results suggested that the RAS could also be activated in rat bladder tissue by continuous hyperglycemia. The bladder weight was increased by diuresis compared to that of control rats, so that the STZ-induced hyperglycemia increased the rat bladder weight more than that of diuretic rats. These findings suggested that an increase in bladder weight could be induced by chronic mechanical stress to the rat bladder wall by diuresis, and that contentious hyperglycemia could further increase the rats' bladder weight.

Interestingly, the AT1 receptor was highly expressed in STZ-induced diabetic rat bladders, although expression of AT1 receptors of diuretic rats did not change in comparison to the control rats. This suggested that the activation of the RAS might occur in STZ-induced diabetic rat bladder tissue.
It is now accepted that blockade of the RAS can contribute to improving the pathogenesis of diabetic nephropathy, and angiotensin receptor blockers (ARBs) are now commonly used in clinical practice. It is unknown whether ARBs can improve the pathogenesis of diabetic cystopathy. However, the present findings indicate that an investigation of the potential of ARBs to prevent or treat diabetic cystopathy is warranted.

\section{Conclusion}

In this study, we demonstrated that expression of AT1 receptors was enhanced by severe hyperglycemia in a rat diabetic model. The local RAS in the rat bladder might be activated by the continuous hyperglycemia caused by STZ administration. 


\section{References}

$>1$ Moller CF, Olesen KP: Diabetic cystopathy. IV: micturition cystourethrography compared with urodynamic investigation. Dan Med Bull 1976;23:291-294.

$>2$ Michel MC, Mehlburger L, Schumacher H, Bressel HU, Goepel M: Effect of diabetes on lower urinary tract symptoms in patients with benign prostatic hyperplasia. J Urol 2000; 163:1725-1729.

$>3$ Cheng EY, Decker RS, Lee C: Role of angiotensin II in bladder smooth muscle growth and function. Adv Exp Med Biol 1999;462: 183-191.
4 Kato H, Suzuki H, Tajima S, Ogata Y, Tominaga $\mathrm{T}$, Sato $\mathrm{A}$, Saruta $\mathrm{T}$ : Angiotensin II stimulates collagen synthesis in cultured vascular smooth muscle cells. J Hypertens 1991; 9:17-22.

$>5$ Kang KW: Angiotensin II-mediated Nrf2 down-regulation: a potential causing factor for renal fibrosis? Arch Pharm Res 2011;34: 695-697.

-6 Jia L, Li Y, Xiao C, Du J: Angiotensin II induces inflammation leading to cardiac remodeling. Front Biosci 2012;17:221-231.
7 Uhal BD, Li X, Piasecki CC, Molina-Molina $\mathrm{M}$ : Angiotensin signalling in pulmonary fibrosis. Int J Biochem Cell Biol 2012;44:465468.

8 Yoshiji H, Noguchi R, Ikenaka Y, Kaji K, Aihara Y, Douhara A, Yamao J, Toyohara M, Mitoro A, Sawai M, Yoshida M, Morioka C, Fujimoto M, Uemura M, Fukui H: Combination of branched-chain amino acid and angiotensin-converting enzyme inhibitor improves liver fibrosis progression in patients with cirrhosis. Mol Med Report 2012;5:539-544.

$>9$ Harrison-Bernard LM, Imig JD, Carmines PK: Renal AT1 receptor protein expression during the early stage of diabetes mellitus. Int J Exp Diabetes Res 2002;3:97-108. 